\title{
KONSEP PEMAKAIAN DAUR ULANG GREYWATER UNTUK KEPERLUAN MCK SEKOLAH
}

\author{
Aniek Prihatiningsih ${ }^{1}$, Inda Sumarli ${ }^{2}$, Gregorius S. Sentosa. ${ }^{3}$ dan Alfred J. Susilo ${ }^{4}$ \\ ${ }^{1}$ Program Studi Sarjana Teknik Sipil, Universitas Tarumanagara Jakarta \\ Email: aniekp@ft.untar.ac.id \\ ${ }^{2}$ Program Studi Sarjana Teknik Sipil, Universitas Tarumanagara Jakarta \\ Email: indas@ft.untar.ac.id \\ ${ }^{3}$ Program Studi Sarjana Teknik Sipil, Universitas Tarumanagara Jakarta \\ Email: gregoriuss@ft.untar.ac.id \\ ${ }^{4}$ Program Studi Sanjana Teknik Sipil, Universitas Tarumanagara Jakarta \\ Email: alfred@ft.untar.ac.id
}

\begin{abstract}
Water is one of the natural resources that has very important role in the daily life of all living creatures. Mishandling of water might result in water catastrophe. Associates want to give learning to students regarding the environment, use water wisely, and do greywater recycling. Associates need help to make discussion topic regarding the use and saving also conceptual of greywater recycle for rest room necessity. Water treatment need to be done which is one of important factor to accomplish sustainable development related to our natural resources in this case is water. This devotion aim is to supply material to discuss between teachers and students about water necessity and give understanding to next generation regarding the important of clean water, to use water responsibly and understand greywater recycle. The output of greywater recycling can be used as an alternative water resource to solve the lack of water. Recycled water can be used for toilet and watering plant. Associate's problem solving to introduce self-conscious the important of using water responsibly and also share knowledge about greywater recycle to next generation, by giving presentation to be discuss by students and teachers. Booklet will be use as discussion between students, and also included with conceptual drawing of greywater use for rest room at SMAN 96. Included in this service, prediction calculation of clean water being used per days in SMAN 96 based on teachers, and students during spring semester of 2020/2021 was provided. The calculation based on the number of active individuals at busy days and also according to SNI 037065-2005 and resulted with usage of $67 \mathrm{~m}^{3}$. When calculation was done based on holiday prediction then it will be saved as much $1968 \mathrm{~m}^{3}$ a year.
\end{abstract}

Keywords: water, greywater, recycle, toilet

\begin{abstract}
ABSTRAK
Air merupakan salah satu sumber daya alam yang sangat dibutuhkan dalam kehidupan sehari-hari bagi mahluk hidup. Kesalahan dalam memanfaatkan/pemakaian air dapat mengakibatkan terjadinya krisis air. Mitra berkeinginan untuk melakukan semacam pembelajaran kepada siswa-siswanya tentang lingkungan hidup, pemanfaatan air secara bijak, dan melakukan daur ulang air limbah (greywater ). Mitra meminta dibantu membuatkan bahan diskusi tentang pemakaian dan penghematan serta konsep daur ulang greywater untuk keperluan MCK sekolah. Pengelolaan air perlu dilakukan yang merupakan salah satu bagian penting untuk mewujudkan pembangunan berkelanjutan terkait sumber daya alam yang kita miliki dalam hal ini adalah air. Pengabdian ini bertujuan memberi bantuan berupa bahan-bahan untuk diskusi antara guru dan siswa tentang kebutuhan air serta memberikan pemahaman kepada generasi penerus akan pentingnya air bersih dan menggunakan secara bijak pemakaian air serta mengerti daur ulang greywater. Hasil daur ulang greywater ini dapat dimanfaatkan sebagai sumber air alternatif guna mengatasi defisit air. Air hasil daur ulang dapat digunakan untuk keperluan MCK dan menyiram tanaman. Solusi permasalahan mitra untuk menanamkan kesadaran akan penggunaan air secara bijak serta memberikan pengetahuan akan daur ulang greywater bagi generasi penerus. dengan memberikan bahan presentasi/paparan untuk diskusi antara siswa dan guru. Bahan buku saku yang akan menjadi bahan diskusi diantara siswa, serta gambar konsep Pemakaian Daur Ulang Greywater untuk Keperluan MCK sekolah SMAN 96. Pada pengabdian ini juga dilakukan perhitungan perkiraan kebutuhan air bersih perhari di SMAN 96 berdasarkan dari data guru, tenaga didik dan peserta didik pada semester genap tahun ajaran 2020/2021. Hasil perhitungan ini berdasarkan jumlah manusia yang aktif pada hari sibuk dan perdasarkan peraturan SNI 037065-2005 yang diperoleh di sebanyak $67 \mathrm{~m}^{3}$. Bila dilakukan perhitungan berdasarkan prediksi hari libur maka dapat dilakukan penghematan sebesar $1968 \mathrm{~m}^{3}$ dalam setahun.
\end{abstract}

Kata kunci: air, air limbah, daur ulang, MCK 


\section{PENDAHULUAN}

Sekolah yang menjadi mitra dalam Pengabdian pada Masyarakat ini adalah SMAN 96 yang berlokasi di Jl. Jati Raya No.40, RW.12, Kapuk, Kecamatan Cengkareng, Kota Jakarta Barat, Daerah Khusus Ibukota Jakarta 11730. Berikut gambar-gambar di lingkungan sekolah mitra.

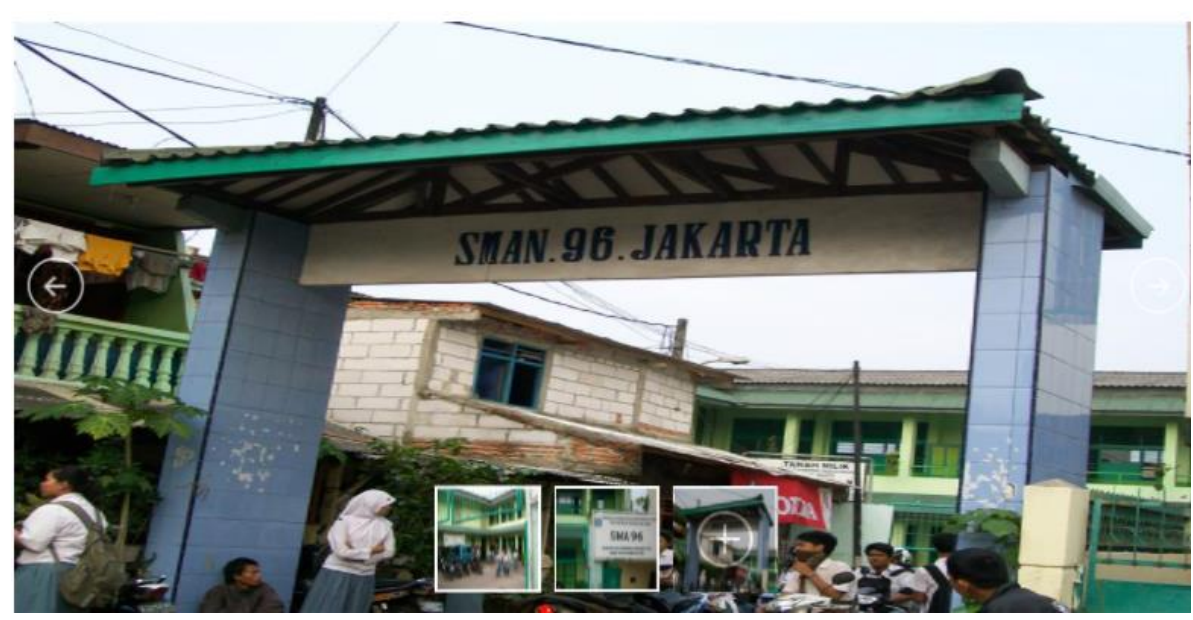

Gambar 1. Gerbang sekolah SMAN 96

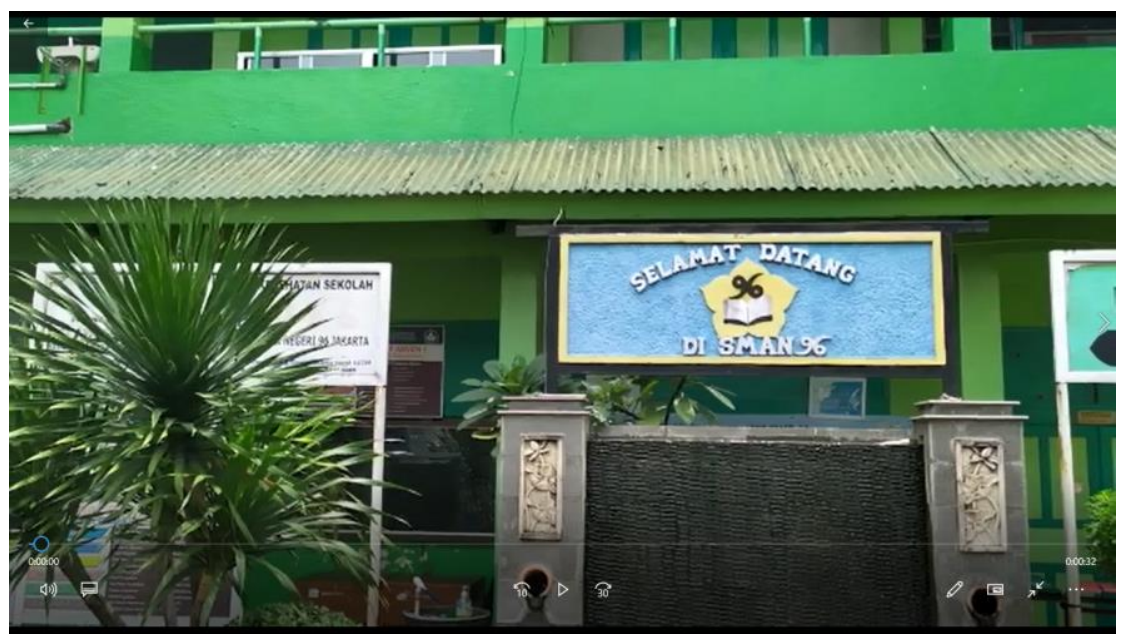

Gambar 2. Gedung SMAN 96

Mitra dalam hal ini diwakili oleh kepala sekolah SMAN 96 Bapak Adil Minita Ginting, M.Si., mempunyai permasalahan bahwa generasi muda sebagai generasi penerus harus sedini mungkin memahami sumber daya air yang semakin menipis. Oleh sebab itu para siswa harus diberi penjelasan tentang pengolahan air limbah untuk bisa dimanfaatkan kembali. Keinginan mitra ini dengan memberikan sosialisasi kepada para siswanya di lingkungan sekolah tentang air bersih, air kotor, air limbah (greywater), bagaimana mengolahnya, memanfaatkan, dan untuk selalu memikirkan penghematan penggunaan air. Pemakaian air yang berlebihan dan tidak bijaksana menyebabkan banyak air terbuang percuma sehingga ketersediaan air semakin menipis. Hal ini menyebabkan perlu dilakukan suatu langkah yang tepat yaitu dengan melakukan penghematan pemakaian air dan melakukan daur ulang air limbah (greywater) untuk dapat dipergunakan sebagai kebutuhan air MCK (Mandi, Cuci, Kakus). 
Untuk menyelesaikan persoalan mitra tersebut akan dibuatkan sebuah konsep pemakaian daur ulang greywater untuk keperluan MCK sekolah berupa gambar, memberikan materi paparan untuk guru, dan memberikan buku saku untuk didiskusikan kepada siswa.

Air limbah yang akan didaur ulang mempunyai kandungan $\mathrm{pH}$ tinggi. Sari, R N, Sunarto dan Wiryanto (2015) mengatakan adanya sisa bahan pembersih dalam air limbah domestik seperti deterjen, sampo, sabun dan pembersih lainnya yang bersifat alkalis dalam air limbah domestik menjadikan limbah tersebut dari $\mathrm{pH}$ rendah menjadi $\mathrm{pH}$ netral kembali.

Suoth, Purwati, Andiri (2018) mengatakan Konsep konsumsi dan produksi berkelanjutan berfokus pada serangkaian upaya pengurangan dampak negatif terhadap lingkungan sepanjang daur hidup produk atau jasa, yang terkait dengan kegiatan masyarakat dalam melakukan produksi dan konsumsi setiap hari. Oleh sebab itu perlu dilakukan daur ulang yang berkelanjutan untuk menjaga agar keseimbangan air di bumi.

\section{METODE PELAKSANAAN PKM}

Tahapan/langkah-langkah metode pelaksanaan pengabdian kepada masyarakat tentang konsep pemakaian daur ulang greywater untuk keperluan MCK sekolah sebagai berikut:

1. Melakukan studi literatur tentang greywater

2. Melakukan survei ke lapangan untuk mendapatkan data primer dengan foto dan vidio

3. Mencari data sekunder melalui internet

4. Melakukan kompilasi data yang sudah diperoleh

5. Mempelajari beberapa konsep tentang pengolahan air limbah

6. Melakukan perhitungan kebutuhan air bersih dengan prediksi hari sibuk, libur dan sekolah tutup.

7. Melakukan analisis dan pembahasan untuk pembuatan konsep pengolahan greywater

8. Membuat persiapan konsep menghasilkan gambar konsep daur ulang greywater

9. Membuat bahan presentasi, untuk bahan diskusi antara guru dan murid

10. Membuat buku saku, sebagai bahan pembelajaran dan dibagikan kepada siswa untuk didiskusikan

11. Memberikan hasil PKM berupa konsep daur ulang greywater, bahan presentasi, dan buku saku yang disampaikan dalam bentuk soft copy.

Berikut diagram alir pengabdian kepada masyarakat:

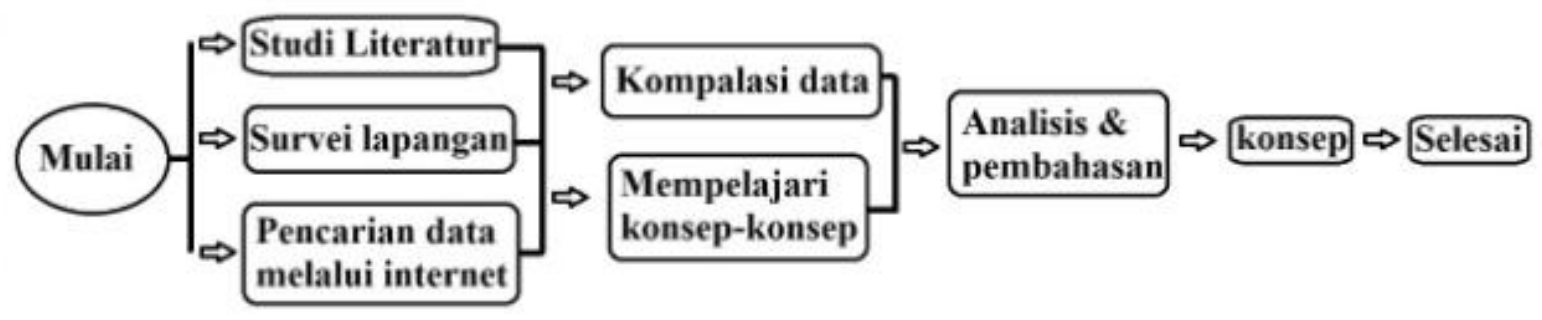

Gambar 3. Diagram alir kegiatan pengabdian kepada masyarakat 


\section{HASIL DAN PEMBAHASAN}

Hasil pelaksanaan kegiatan pengabdian kepada masyarakat ini berjalan dengan baik dan lancar. Kegiatan diawali dengan melakukan survai ke lokasi mitra dan mendapatkan data-data Guru, Tenaga Didik, dan Peserta Didik SMAN 96 Semester Genap Tahun Ajaran 2020/2021, yang diperoleh dari internet pertanggal 10 Juni 2021 seperti pada Tabel 1.

Tabel 1. Jumlah Data Guru, Tenaga Didik, dan Peserta Didik SMA 96 Semester Genap Tahun Ajaran 2020/2021 (https://dapo.kemdikbud.go.id/sekolah/D47EA3A23DFE5A9518C9)

\begin{tabular}{lcccc}
\hline \multicolumn{1}{c}{ Uraian } & Guru & Tekdik & PTK & PD \\
\hline Laki & 15 & 10 & 25 & 326 \\
\hline Perempuan & 26 & 4 & 30 & 456 \\
\hline Total & 41 & 14 & 55 & 782 \\
\hline
\end{tabular}

Keterangan:

Data rekap pertanggal 10 Juni 2021

Penghitungan PTK adalah yang sudah mendapat penugasan, berstatus aktif dan terdaftar di sekolah induk.

Singkatan: $\quad$ 1. PTK = Guru ditambah Tendik

2. $\mathrm{PD}=$ Peserta Didik

Berikut adalah foto-foto hasil survei kelokasi lapangan:

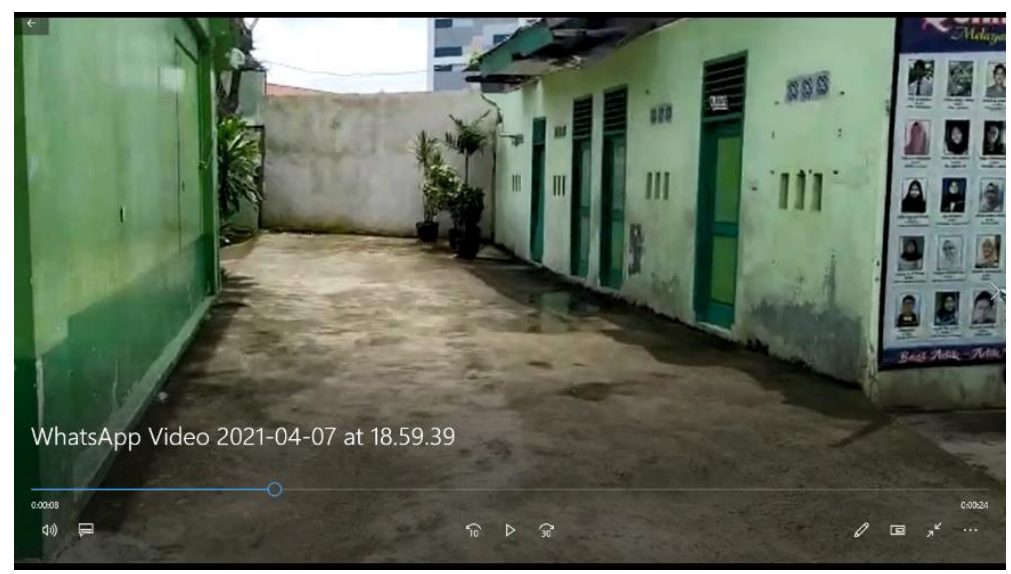

Gambar 4. Kamar mandi dan WC dilingkungan sekolah

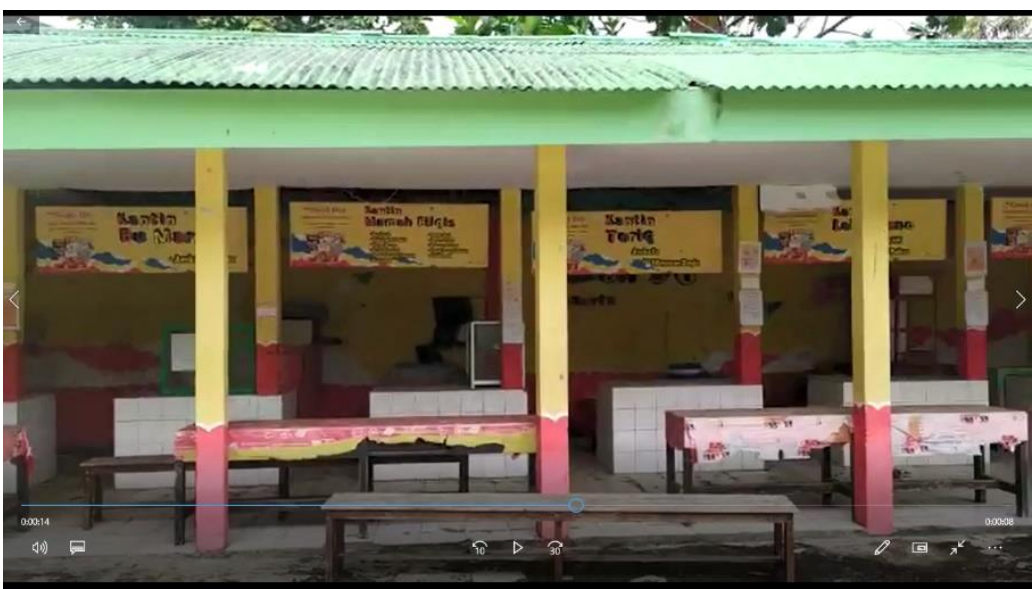

Gambar 5. Kantin di lingkungan sekolah 


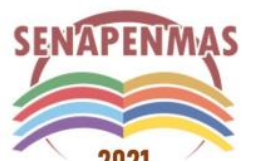

2021
Seminar Nasional Hasil Penelitian dan Pengabdian Kepada Masyarakat 2021

Pengembangan Ekonomi Bangsa Melalui Inovasi Digital Hasil Penelitian dan Pengabdian Kepada Masyarakat Jakarta, 21 Oktober 2021

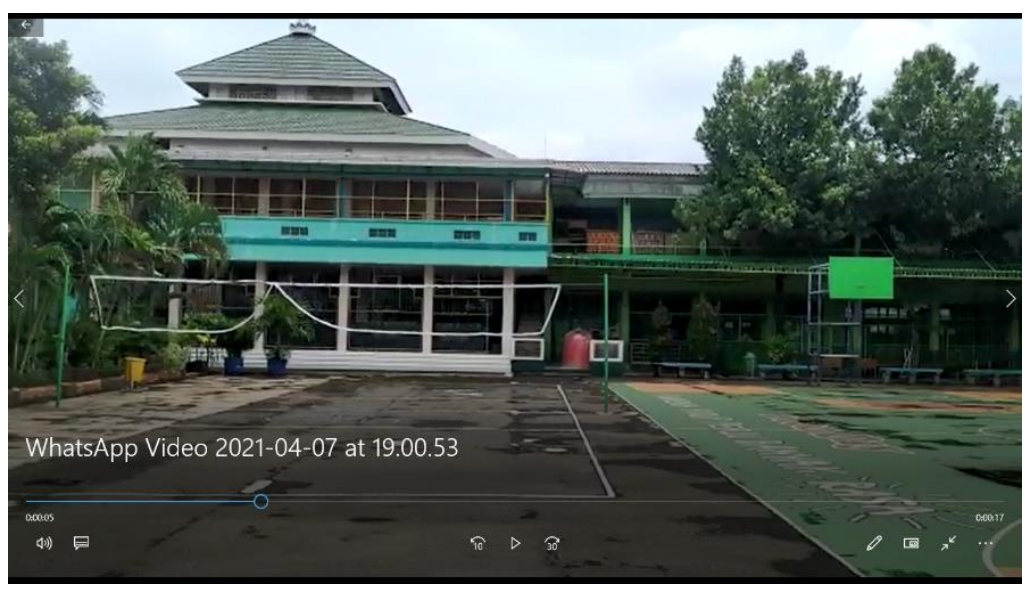

Gambar 6. Masjid di lingkungan sekolah

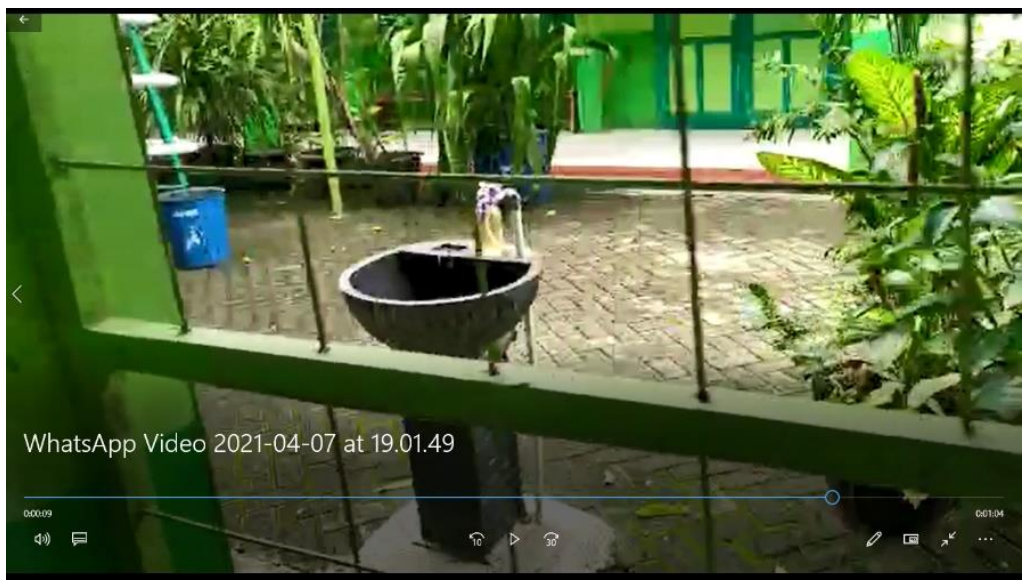

Gambar 7. Wastafel yang ada dilingkungan sekolah

Gambar 4 sampai dengan 7 merupakan foto-foto sumber air limbah berupa air hasil buangan dari kamar mandi/toilet, kantin, masjid, dan wastafel.

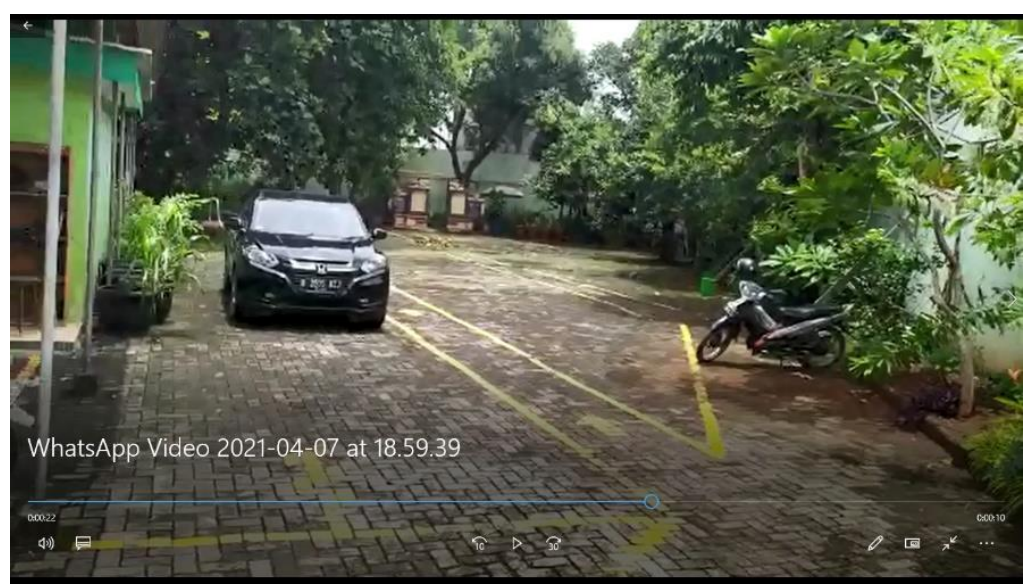

Gambar 8. Halaman parkir di lingkungan sekolah 


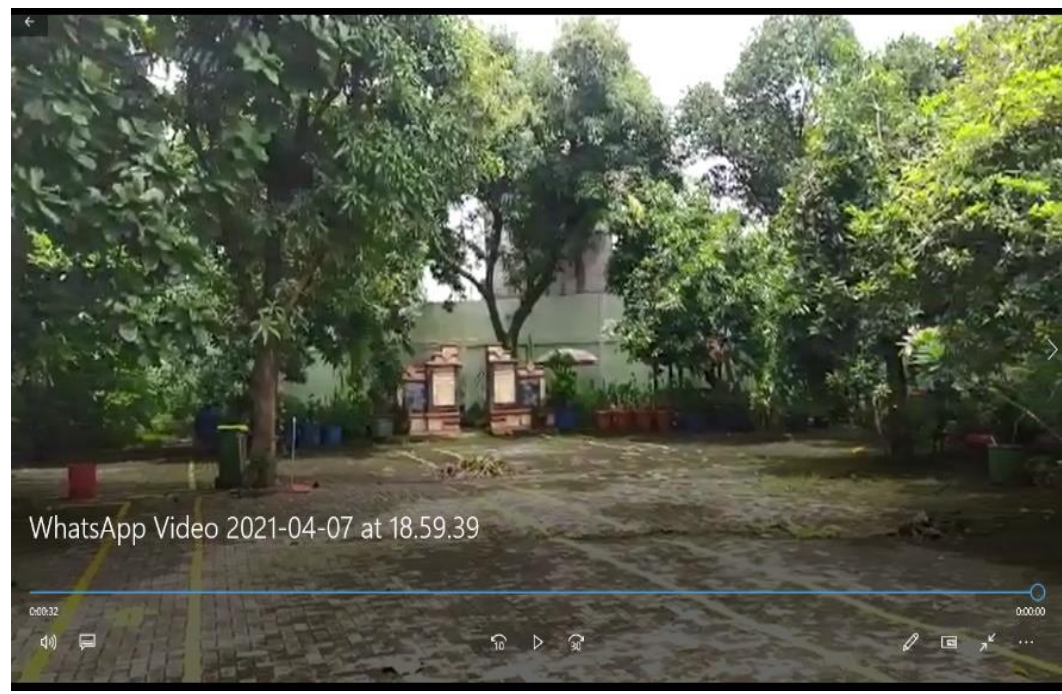

Gambar 9. Halaman parkir dilingkungan sekolah

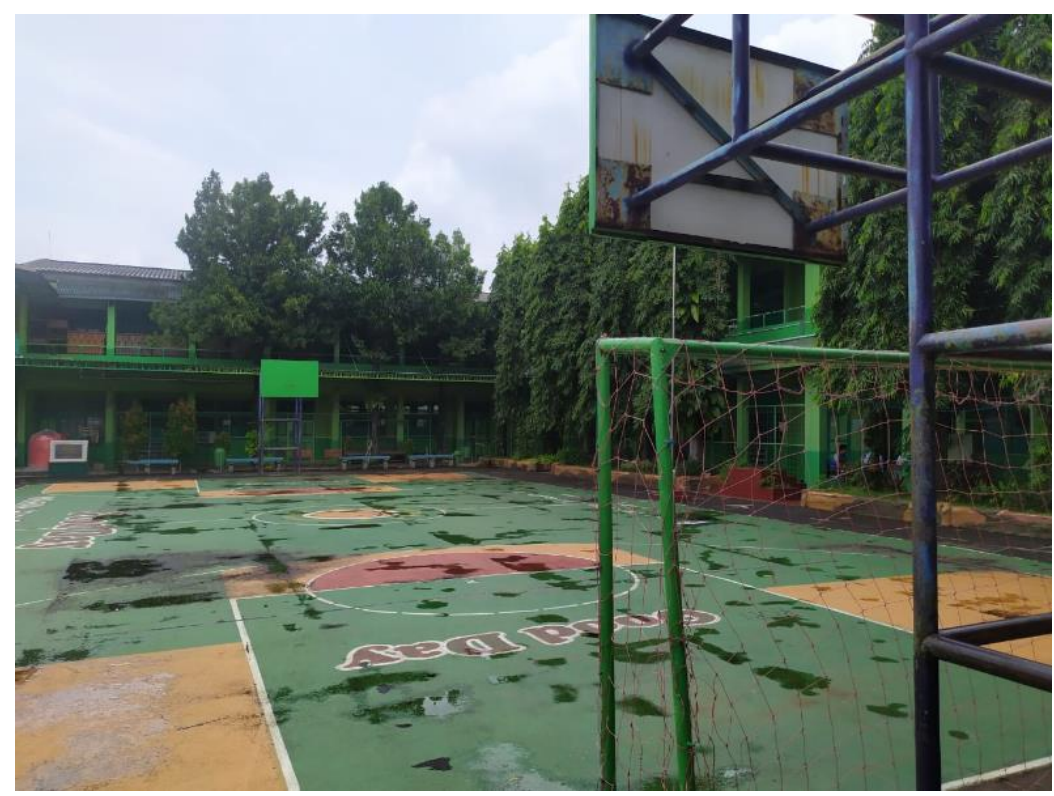

Gambar 10. Lapangan basket dilingkungan sekolah

Gambar 8 sampai dengan 9 merupakan foto-foto yang ada di lingkungan sekolah yang memerlukan air untuk penyiraman.

Berdasarkan peraturan SNI 037065-2005 kebutuhan akan air bersih untuk sekolah SMA sebanyak 80 liter/siswa/hari. Dengan menggunakan data jumlah TPK (Guru ditambah Tendik) ada 55 orang, jumlah siswa 782 orang, sehingga total yang menggunakan air perhari 837 orang. Dengan denikian keperluan air perhari di sekolah SMAN 96 sebesar 66.960 liter, atau sekitar 67 $\mathrm{m}^{3}$. Besaran ini pada kondisi sekolah tidak libur.

Berdasarkan data lapangan adanya kamar mandi/toilet, wastafel. Masjid, dan kantin, maka air yang akan didaur ulang diambil dari tempat tersebut. Untuk air yang masuk ke WC tidak diperhitungkan. Bila air limbah ini dapat didaur ulang, maka sebagian kebutuhan air bersih dapat dikurangi. Air daur ulang ini dapat digunakan untuk pamakaian MCK dan menyiram tanaman. 


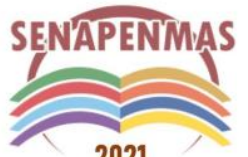

2021
Seminar Nasional Hasil Penelitian dan Pengabdian Kepada Masyarakat 2021 Pengembangan Ekonomi Bangsa Melalui Inovasi Digital Hasil Penelitian dan Pengabdian Kepada Masyarakat Jakarta, 21 Oktober 2021

Selain telah melakukan penghematan juga menjaga bumi terhadap kekeringan dan kekurangan air dimasa yang akan datang.

Bila pemakaian $67 \mathrm{~m}^{3}$ yang digunakan untuk seluruh keperluan sehari-hari dari menyiram WC, mencuci kaki (dari kamar mandi), sebagai air wudhu, untuk cuci tangan, dan untuk mencuci piring diasumsikan 50\% yang akan didaur ulang. Sedangkan 50\% lagi dianggap untuk menyiram WC dan tidak akan didaur ulang. Air limbah yang akan didaur ulang sebanyak 50\% ditampung pada wadah yang berbeda untuk WC dan selanjutnya dilakukan daur ulang untuk digunakan menyiram WC dan tanaman. Setidaknya dalam satu hari sudah dilakukan penghematan kurang lebih $33,5 \mathrm{~m}^{3}$.

Dari hasil perhitungan di atas dapat diprediksi penghematan air untuk SMAN 96 dan dengan asumsi hari libur dan jumlah manusia yang beraktifitas setiap harinya. Prediksi penghematan seperti terlihat pada Tabel 2.

Tabel 2. Prediksi penghematan air

\begin{tabular}{ccl}
\hline No & Volume & Prediksi penghematan air \\
\hline 1 & $33,5 \mathrm{~m}^{3}$ & $\begin{array}{l}\text { / hari dengan asumsi 50\% yang didaur ulang, } \\
\text { merupakan hari sibuk (Senin sampai Jumat) dan } \\
\text { seluruh siwa, guru dan pedik hadir }\end{array}$ \\
\hline 2 & $2 \mathrm{~m}^{3}$ & $\begin{array}{l}\text { / hari dengan asumsi 5\% yang didaur ulang hanya } \\
\text { pada Sabtu dan Minggu, yang hadir hanya } \\
\text { satpam, maka dipredisi penggunaan air hanya 5\% }\end{array}$ \\
\hline 3 & $4 \mathrm{~m}^{3}$ & $\begin{array}{l}\text { / hari dengan asumsi 10\% yang didaur ulang } \\
\text { hanya pada bulan Desember, Januari, Mei, dan } \\
\text { Juni dimana siswa libur, yang hadir hanya Guru } \\
\text { dan pendik. }\end{array}$ \\
\hline 4 & $186 \mathrm{~m}^{3}$ & \begin{tabular}{l} 
Penghematan dalam sebulan pada kondisi sibuk \\
\hline 5
\end{tabular} \\
\hline $1968 \mathrm{~m}^{3}$ & Penghematan dalam setahun. \\
\hline
\end{tabular}

Berdasarkan analisis dan pembahasan, maka konsep yang diusulkan untuk SMAN 96 seperti terlihat pada gambar 11. yang merupakan gambar hasil dari tim pengabdian kepada masyarakat. 


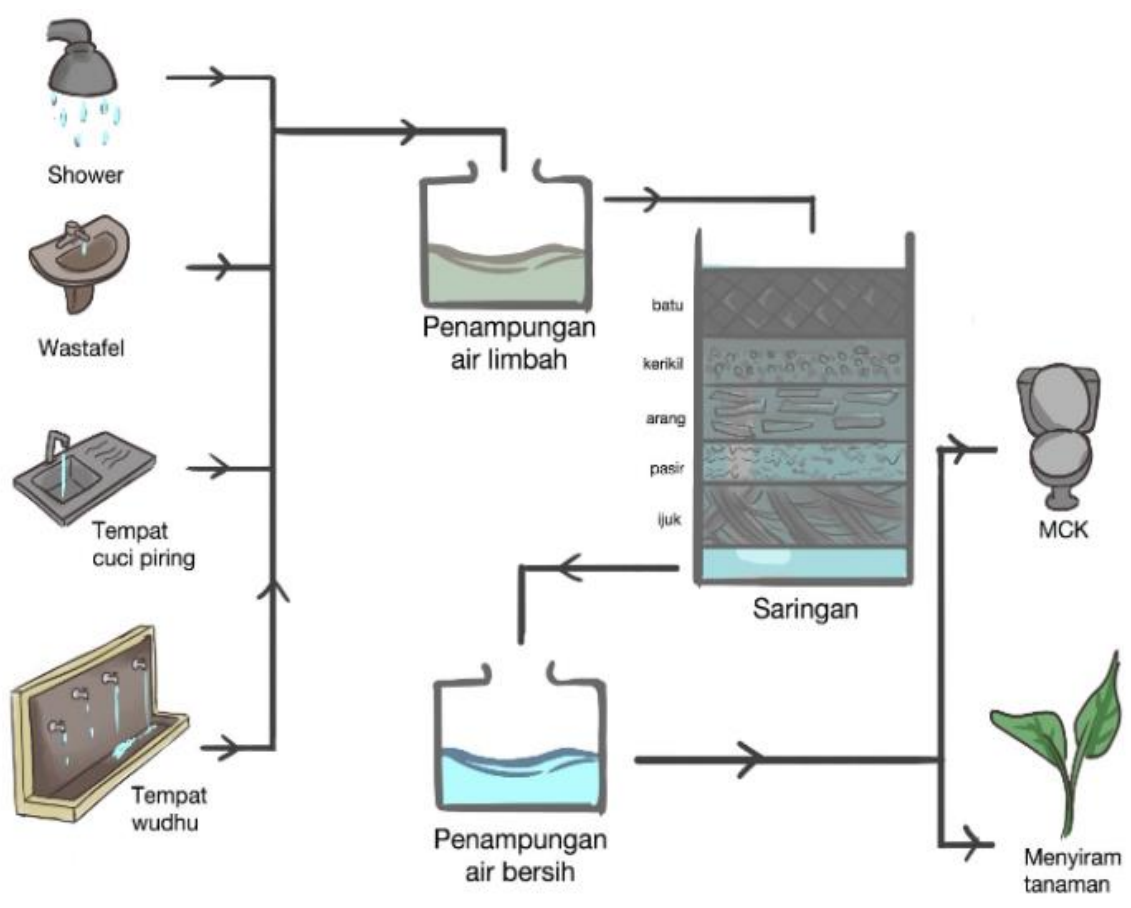

Gambar 11. Usulan Konsep Daur Ulang Dengan Saringan Sederhana.

Dapat dilihat bahwa greywater yang akan didaur ulang berasal dari kamar mandi, wastafel (tempat cuci tangan yang berada di sekitar sekolah), tempat cuci piring yang berasal dari kantin, dan air dari tempat wudhu di masjid sekolah. Air limbah tersebut ditampung dalam pemampungan air limbah yang kemudian dilakukan penyaringan sederhana. Lapisan penyaringan ini terdiri dari ijuk, pasir, arang, kerikil, dan batu. Setelah disaring dilakukan penampungan air bersih yang kemudian dapat disalurkan untuk digunakan sebagai pembersih toilet (MCK) dan menyiram tanaman serta untuk membersihkan halaman sekolah.

\section{KESIMPULAN DAN SARAN}

1. Dari hasil survei di lokasi pemakaian air bersih di lingkungan SMAN 96 untuk keperluan kamar mandi/toilet, air dari kantin, masjid, wastafel, menyiram tanaman.

2. Dilokasi terdapat 4 sumber air limbah berupa kamar mandi/toilet, air dari kantin, masjid, dan wastafel sesuai gambar 4 sampai dengan 7 .

3. Prediksi perhitungan air bersih berdasarkan data guru, tenaga pendidik, dan peserta didik pada semester genap tahun ajaran 2020/2021 dengan prediksi hari sibuk, libur dan sekolah tutup seperti terlihat pada tabel 2.

4. SMAN 96 harus melaksanakan sosialisasi kepada siswanya mengenai pentingnya kegiatan daur ulang untuk menghenat air.

\section{Ucapan Terima Kasih}

Pengabdian Kapada Masyarakat ini didanai oleh LPPM Periode I tahun 2021 Universitas Tarumanagara. Tim PKM mengucapkan terima kasih kepada Ketua Lembaga Penelitian dan Pengabdian Kepada Masyarakat Universitas Tarumanagara yang mendukung pembiayaan penelitian ini, Ir. Jap Tji Beng MMSI, Ph.D dan staf Lembaga Penelitian dan Pengabdian Kepada Masyarakat Universitas Tarumanagara. Terima kasih juga disampaikan kepada Ketua 


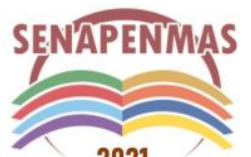

2021
Seminar Nasional Hasil Penelitian dan Pengabdian Kepada Masyarakat 2021 Pengembangan Ekonomi Bangsa Melalui Inovasi Digital Hasil Penelitian dan Pengabdian Kepada Masyarakat Jakarta, 21 Oktober 2021

Program Studi Sarjana Teknik Sipil, Dr. Widodo Kushartomo. Semoga PKM ini dapat bermanfaat bagi SMAN 96 Jakarta.

\section{REFERENSI}

Alfrida E. Suoth, Sri Unon Purwati, dan Yuriska Andiri (2018), Pola Konsumsi Air Pada Perumahan Teratur: Studi Kasus Konsumsi Air Di Perumahan Griya Serpong Tangerang Selatan, Ecolab Vol. 12 No. 2, halaman 53 - 102

Sari, R N, Sunarto dan Wiryanto (2015), Analisis komparasi kualitas air limbah domestik berdasarkan parameter biologi dan fisika di IAL Semanggi dan IPAL Mojosongo, Jurnal Ekosains, Vol VII, No. 2, halaman 62 - 74

SNI 037065-2005 Tata Cara Perencanaan Sistem Plambing, Badan Standarisasi Indonesia, halaman 4 
Seminar Nasional Hasil Penelitian dan Pengabdian Kepada Masyarakat 2021

SENAPENMAS

Pengembangan Ekonomi Bangsa Melalui Inovasi Digital Hasil Penelitian dan

Pengabdian Kepada Masyarakat

Jakarta, 21 Oktober 2021

(halaman kosong) 